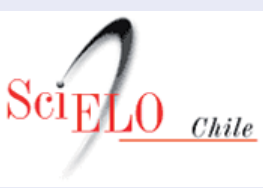

www.scielo.cl

Rev Chil Pediatr. 2017;88(3):431-433

DOI: 10.4067/S0370-41062017000300019

CARTA AL EDITOR

\section{Malformaciones nefro-urológicas en niños con síndrome de Down}

\section{Nephro-urological malformations in children} with Down syndrome

\section{Sr. Editor:}

Entre las causas de morbimortalidad hospitalaria en niños con síndrome de Down (SD) publicado recientemente en su revista por Lizama y cols. ${ }^{1}$, llama la atención la ausencia de problemas relacionados con el riñón y las vías urinarias, a excepción de 2 pacientes que presentaron infección urinaria. Esta situación, según explican los autores, pudo deberse a que las patologías urológicas quirúrgicas se hospitalizaron en un servicio distinto al que se desarrolló este estudio. En relación a ello, me pareció importante entregar información sobre la prevalencia descrita de malformaciones nefro-urológicas (MNU) en pacientes con SD. En un amplio registro retrospectivo de malformaciones congénitas en el estado de Nueva York por más de una década, Kupferman y cols. observaron que la prevalencia de MNU en niños con SD menores de 2 años fue de $3,2 \%$, comparado con $0,7 \%$ en población sin $\mathrm{SD}$, o sea 4 a 5 veces más frecuente, destacando especialmente la obstrucción uretral anterior, el riñón displástico multicístico, las hidroureteronefrosis obstructivas, las válvulas uretrales posteriores, el síndrome de prune-belly y la agenesia renal ${ }^{2}$. En un estudio nacional estadounidense previo, Cleves y cols. destacan a las malformaciones génito-urinarias como las anomalías más comunes detectadas en SD, después de las anomalías cardíacas y gastrointestinales, siendo los problemas obstructivos de vía urinaria la MNU más frecuente ${ }^{3}$. También han sido descritas múltiples alteraciones morfológicas y funcionales re- nales en este grupo de pacientes ${ }^{2}$, aunque no parece claro que exista un tipo específico de anomalía. En 69 pacientes con SD, Málaga y cols. destacan una alta incidencia de hiperuricosuria $(24,2 \%)$ y una preocupante incidencia de daño renal crónico con baja velocidad de filtración glomerular en un 4,5\% de ellos ${ }^{4}$. En vista de estos antecedentes, y ante la alta prevalencia de SD en nuestro país (2,5/1.000 nacidos vivos, la más alta de latinoamérica $)^{1,5}$, me parece adecuado sugerir el incorporar la evaluación por imágenes del sistema urinario en el tamizaje neonatal del SD, e incorporar pruebas de función renal en el seguimiento de estos pacientes, de manera de obtener diagnósticos precoces, y lograr la prevención de posibles complicaciones nefro-urológicas futuras.

\section{Referencias}

1. Lizama M, Cerda J, Monge M, Carrillo I, Clavería C, Castillo A. Morbimortalidad hospitalaria en niños con síndrome de Down. Rev Chil Pediatr 2016;87:102-9.

2. Kupferman J, Druschel C, Kupchnik S. Increased prevalence of renal and urinary tract anomalies in children with Down syndrome. Pediatrics 2009;124:e615-21.

3. Cleves M, Hobbs C, Cleves P, Tilford J, Bird T, Robbins J. Congenital defects among liveborn infants with Down syndrome. Birth Defects Res A Clin Mol Teratol 2007;79: 657-63.

4. Málaga S, Pardo R, Málaga I, Orejas G, Fernández-Toral J. Renal involvement in Down syndrome. Pediatr Nephrol 2005;20:614-7.

5. Nazer J, Cifuentes L. Prevalencia al nacimiento de malformaciones congénitas en las maternidades chilenas participantes en ECAMC en el período 2001-2010. Rev Med Chile 2014;142:1150-6.

\author{
Dr. Felipe Cavagnaro SM. \\ Nefrólogo Pediátrico \\ Clínica Alemana de Santiago \\ Facultad de Medicina Clínica Alemana- \\ Universidad del Desarrollo
}

